\title{
Near-Death Experiences and the Measurement of Blood Gases
}

\author{
Michael D. Gliksman, M.P.H., F.A.C.O.M. \\ Sydney University \\ Allan Kellehear, Ph.D. \\ La Trobe University
}

\begin{abstract}
Although cerebral anoxia is not thought to be responsible for triggering near-death experiences (NDEs), the issue is not so clear in the case of hypercapnia. Detection of normal blood gases in Michael Sabom's (1982) case study seems to be the major reply to suggestions that hypercapnia may have a causal role in NDEs. We argue, however, that routine arterial measures of blood gases are not a reliable indicator of cerebral levels.
\end{abstract}

Raymond Moody (1977), Kenneth Ring (1980), and Michael Sabom (1982) have discussed the role of cerebral anoxia and/or hypercapnia in stimulating the features of the near-death experience (NDE). In those discussions, all three authors minimized the role of cerebral anoxia (oxygen deprivation of the brain) on the grounds that (1) visionary aspects of the NDE have been reported by people who were fully conscious, and (2) hypoxic conditions give rise to mental states such as mental laziness, irritability, slowness of reasoning, and difficulty of remembering. These are contrary to the cognitive experiences regularly reported by NDErs.

Recently, however, Moody (1988) has focused attention on the possi-

Dr. Gliksman is Research Fellow in the Department of Community Medicine at Sydney University, Australia, and Dr. Kellehear is a Lecturer in the Department of Sociology at La Trobe University. Requests for reprints should be addressed to Dr. Kellehear at the Department of Sociology, La Trobe University, Bundoora, 3083, Australia. 
ble role of hypercapnia (elevated arterial levels of carbon dioxide) in stimulating the tunnel sensation and the feeling of being surrounded by bright lights. Nevertheless, he questioned the role of carbon dioxide overload by referring to Sabom's (1982) case study of a patient whose blood gas levels were measured at the time of the patient's NDE. But how reliable is the measure of arterial blood gases as an indicator of those levels in the central nervous system?

Sabom's (1982) account of the case recorded that the blood taken from the patient's femoral artery showed above-normal levels of oxygen $\left(\mathrm{pO}_{2}=138\right)$ and lower than normal carbon dioxide levels $\left(\mathrm{pCO}_{2}=\right.$ 28; $\mathrm{pH}=7.46$ ). The assumption behind this case, and Moody's reference to it, seems to be that peripheral measures are, in fact, a reliable measure of central nervous system levels. Recent experimental evidence, however, calls this assumption into question.

In a study examining blood gases as a quantitative measure of brain death, Edward Benzel, Charles Gross, Theresa Hadden, Lee Kesterson, and Michael Landreneau (1989) measured the rate of rise in peripheral arterial carbon dioxide in 20 critically ill patients after respiration had ceased. Resuscitation was not attempted. The rate of increase was found to be slow and erratic and in a number of patients the level had risen less than $10 \mathrm{~mm} \mathrm{Hg}$ above normal levels $(40 \mathrm{~mm} \mathrm{Hg}$ ) after 12 minutes.

Another study, using rabbits as subjects (Takeichi, Tokunaga, Maeiwa, Okada, Kambara, Nii, Nanishi, and Oka, 1986), found that tissue metabolism continues for a significant time after cessation of respiration and circulation. This is by no means a new observation, but the unique attribute of this study lies in its quantification of the degree of metabolism by comparison of oxygen levels in venous and arterial blood. Significantly lower levels of oxygen were found in the tissues than would have been gauged from the measurement of arterial blood gases alone.

These two studies demonstrate that care must be taken in equating relatively normal arterial blood gases with normal tissue oxygenation and carbon dioxide levels when death is near. This is especially so when considering the metabolically very active brain.

However, the above observations are not the only problems with interpreting Sabom's case study. Hypocapnia (lower than normal levels of carbon dioxide) is known to reduce blood flow, which can lead to hypoxia in the brain, even when the arterial oxygen content is normal (Hopewell, 1985). Thus Sabom has not eliminated the possibility that anoxia is associated with the NDE he described, irrespective of other arguments about the importance of anoxia in NDEs. 
Finally, if the cerebral blood gases were normal in at least some NDErs, then in what physiological sense can these people be said to be near death? In attempting to dismiss physiological explanations of the NDE with physiological arguments, researchers risk accepting the primacy of physiology in explaining the NDE, when it is not clear whether such a pivotal role is warranted.

As Moody (1988) himself cautioned, we need much more research before we can come to any firm conclusions on the role of blood gases and the NDE. However, we suggest that current arterial measures are not helpful in our understanding of this problem. Routine measures of blood gases in normal hospital settings do not appear to offer reliable information that will shed light on the relationship or meaning of blood gas saturation in organs, such as the brain, and the occurrence of NDEs.

Precisely identifying physiological correlates is important for our search for a greater understanding of the biological mechanism behind the NDE. However, these searches will not necessarily resolve the questions of cause or significance of the NDE, because these questions are, at least in part, also philosophic ones. When the physiological processes responsible for NDEs become clear, this should not necessarily lead to the reductionist conclusion that NDEs are simply their byproduct. As Stanislav Grof and Joan Halifax (1977) have indicated, these processes may simply be the reorienting trigger mechanism of one reality toward another.

\section{References}

Benzel, E.C., Gross, C.D., Hadden, T.A., Kesterson, L., and Landreneau, M.D. (1989). The apnea test for the determination of brain death. Journal of Neurosurgery, 71, 191-194.

Grof, S., and Halifax, J. (1977). The human encounter with death. New York, NY: Dutton.

Hopewell, P.C. (1985). Critical care. In Wyngaarden, J.B., and Smith, L.H. (eds.), Cecil textbook of medicine (pp. 463-482). Baltimore, MD: Saunders.

Moody, R.A. (1977). Reflections on life after life. St. Simon's Island, GA: Mockingbird.

Moody, R.A. (1988). The light beyond. New York, NY: Bantam.

Ring, K. (1980). Life at death: A scientific investigation of the near-death experience. New York, NY: Coward, McCann and Geoghegan.

Sabom, M.B. (1982). Recollections of death: A medical investigation. New York, Harper and Row.

Takeichi, S., Tokunaga, I., Maeiwa, M., Okada, K., Kambara, K., Nii, H., Nanishi, K., and Oka, T. (1986). Experimental studies on death by fire in automobiles and exhaust gas poisoning. American Journal of Forensic Medical Pathology, 7, 301-304. 